\section{Intimacy with Objects}

by Heather Frasch

"Technology is not something that is simply added to the body from the outside. Technology is a supplement, an aspect of the body that adds to it while it qualitatively alters that very body..." [Manning 2007, p. xxii]

Blurred Categories:

Techno-limbs: contact lenses, glasses, ....

Techno-tools: pencils, paper, flute, computer, ....

.... nuanced extensions of my physical body.

Sonic creations:

kinetic sound sculptures, digital instruments, haptic interfaces, manipulated objects ....

.....intentionally focusing on micromotion for heightened intimacy.

Blurred Categories :

composition, instrument, object, form, performance, installation

"We find it familiar to consider objects as useful or aesthetic, as necessities or vain indulgences. We are on less familiar ground when we consider objects as companions to our emotional lives or as provocations to thought. The notion of evocative objects brings together these two less familiar ideas, underscoring the inseparability of thought and feeling in our relationship to things" [Turkle 2007, p. 5]

My instrument, Digital Boxes (image 1, p. 9), intentionally hides performative activity behind an assembly of cigar boxes. Referencing acousmatic listening, the electronics, sensors, objects, and performer's actions are not revealed to the audience.

The boxes themselves hint at a symbolism of something secret, saved or unknown. They do not depict, but allude.

"A symbol is only a true symbol when it is inexhaustible and unlimited in its meaning, when it utters in its arcane language of hint and intimation something that cannot be set forth, that does not correspond to words. It has many faces and many thoughts, and in its remotest depths it remains inscrutable" [Tarkovsky 1989, p. 47]

My composition "I touch what I cannot quite reach..." uses shadows projected onto rice paper in the place of 


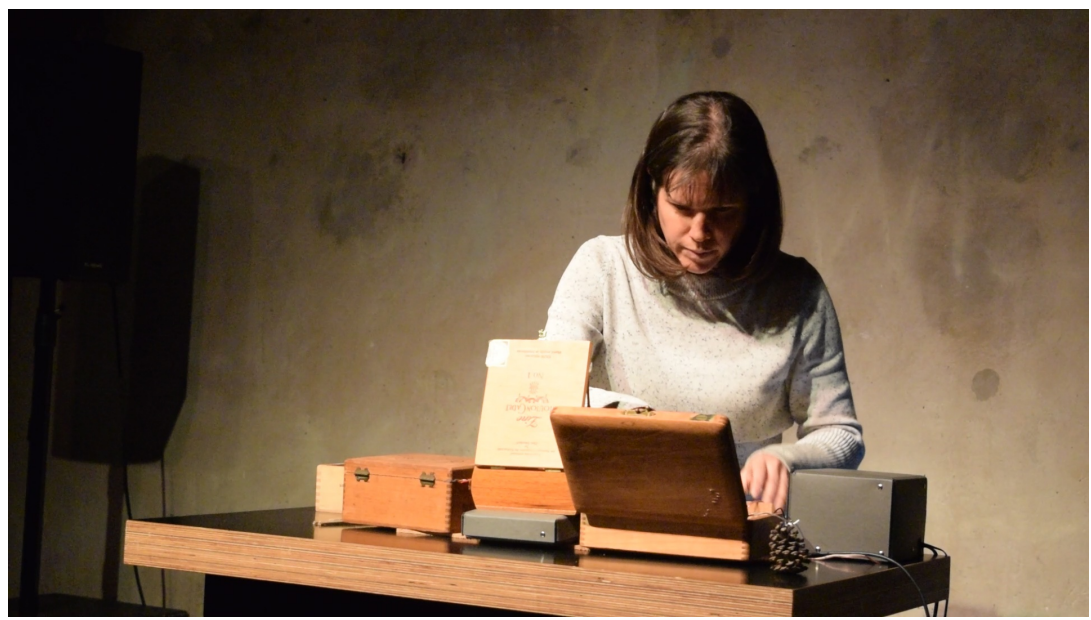

Heather Frasch, Digital Boxes, www.heatherfrasch.net/digital boxes (Oct, 15. 2019). Photographer: Karin Weissenbrunner.

lids of modified boxes to amplify the motion of small kinetic sound sculptures. Quivering materials are unveiled while still obscured.

In this project and that of the cigar boxes, the presence of the 'seen' and lack of presence of the 'unseen' evoke poetical meaning.

Their focus is on the vibrancy of the material - physical and sonic.

"Sensation is a state in which action, perception, and thought are so intensely performatively mixed that their inmixing falls out of itself. Sensation is fallout from perception" [Massumi 2002 in: Manning p. 97-98]

Influenced by the writings of Gaston Bachelard, who uses the memory of "houses as a tool for analysis of the human soul" [Bachelard, p. xxxvi], my composition "weaving broken threads" uses objects that remind me of past places I've lived: acorns and pine cones from the trees on the front lawn of my childhood home; pencils from my anti-modern technology phase in Philly; wooden slates like the ceiling beams in my beloved apartment in Lyon, France. In the compositional process, I build connections among 
these places: places I wasn't ready to leave, others I stayed longer than I should have, places where I felt alone, places with big windows, others with quirky curves... As a modular composition, it allows me to examine a range of connections between self, memory and objects.

\section{"Sensation is an event. It creates} spaces for experience as well as gaps, holes, emptiness and losses. 'Meaning' is not guaranteed." [Manning 2007, p. 45]

\section{References}

Bachelard, G. The Poetics of Space. Presses Universitaires de France 1958, Translation: Orion Press, Inc, 1964. Frasch, H., www.heatherfrasch.net/ stillstretched (Oct. 15, 2019). Manning, E. The Politics of Touch: Sense, Movement, Sovereignty, University of Minnesota Press. 2007. Tarkovsky, A. Sculpting in Time, Translation by Kitty Hunter-Blair, University of Texas Press 1989.

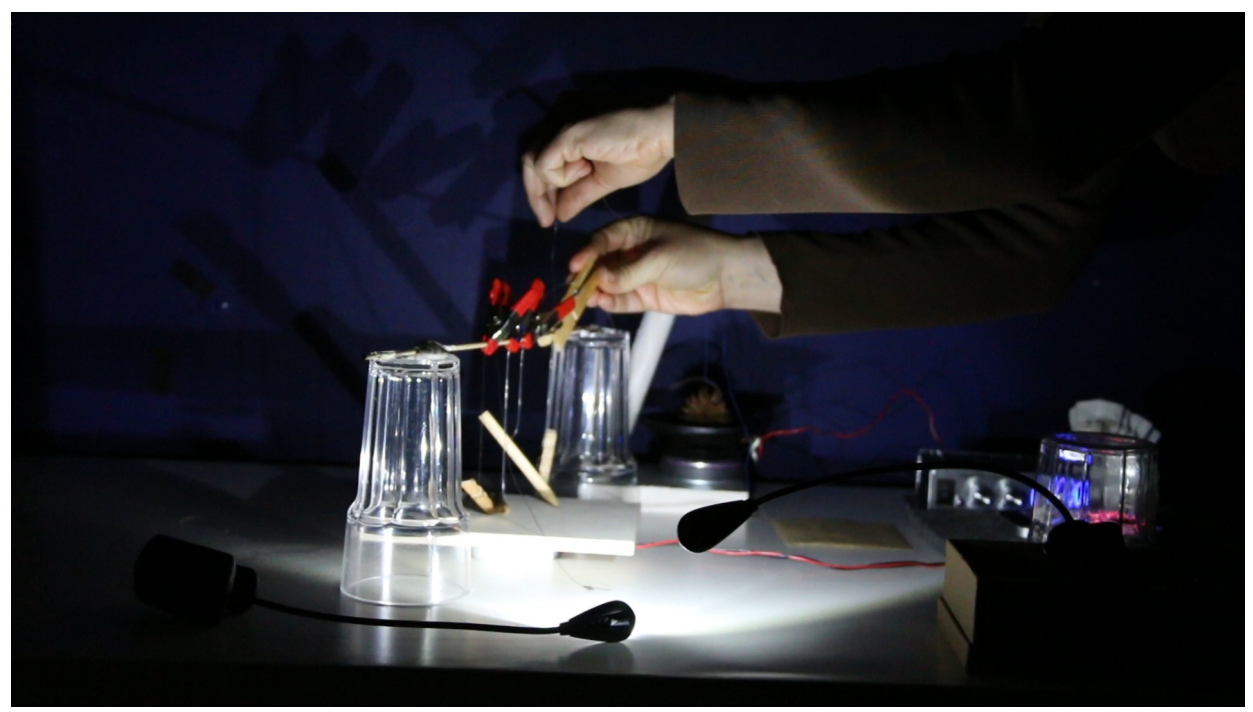

Heather Frasch, sonic creations for performer-composer, www.heather-frasch.squarespace. com/digital-instruments (2018-2019)(Oct, 15. 2019). Photographer: Zunaira Muzaffar. 
Turkle, S. Evocative Objects: Things we Think With, MIT Press 2007.
Initial Remarks on Analyzing

Acousmatic Music from the

Perspective of Multi-agents

by Kıvanç Tatar

Agency and Agents

The notion of agency can be traced back to the age of Enlightenment within the philosophical discussions of whether instrumental rationality or moral norm-based action is the truest expression of human freedom [Emirbayer \& Mische 1998]. The terminology of agency and agents appeared later across disciplines such as Social Sciences, Cognitive Sciences, Applied Sciences, Computer Science. Although there is no consensus on the definition of agency in Social Sciences and Philosophy, an agent is a well-defined term in Computer Sciences, specifically in the fields of Artificial Intelligence and Multi-agent Systems. In their book on Artificial Intelligence (AI), Russell and Norvig [2010] define an agent as "anything that can be viewed as perceiving its environment through sensors and acting upon that environment through actuators."

An agent perceives its environment using sensors while a percept is the sensory data input at any given time. A percept sequence is a histogram of 